\title{
Work schedule flexibility and parking preferences
}

\author{
Wei-Shiuen $\mathbf{~ g g}$ \\ University of California Berkeley \\ wei-shiuen.ng@berkeley.edu
}

\begin{abstract}
The flexibility of work schedule affects the number of commute trips made per week and the number of hours spent at work, which can influence congestion and transportation emission levels. Understanding the linkages between the flexibility of work schedule and travel behavior will provide insights for policies targeted at transportation and parking demand management. This study uses the University of California (UC) Berkeley campus as a study site. UC Berkeley is one of the largest employers in the San Francisco Bay Area with over 11,000 employees, leading to a wide range of employment type, job characteristics, and varying levels of work schedule flexibility. A total of 86 oneon-one interviews were conducted with UC Berkeley employees. This study explores common factors that contribute to UC Berkeley employees' parking preferences and considers how academic discipline or employment type could affect work schedule, which in turn influences travel behavior. Driving is the most popular choice across employment type and job categories. However, not all employees who drive alone have the same parking location preferences. The flexibility of work schedule is one of the key factors that influences parking preferences at the workplace, especially when there are alternative parking locations.
\end{abstract}

Key words: transportation, planning, policy, parking, work schedule

\section{Article history:}

Received: December 1, 2013

Received in revised form: April

17,2015

Accepted: December 31, 2015

Available online: September 7,

2016

\section{$1 \quad$ Introduction}

The University of California (UC) Berkeley campus is one of the largest employers and trip generators in the San Francisco Bay Area region, with more than 36,000 students, 1,377 faculty members and more than 10,000 non-academic staff in 2011 (UCOP 2011; UCOP 2012). UC Berkeley has kept private vehicle use at a relatively low level through moderate parking pricing, promotion of regional transit services, discounted bus passes for students and employees, and ample bike parking. Approximately 9 percent of the faculty and staff surveyed in the 2012 official UC Berkeley Housing and Transportation Survey walked to campus, 22 percent used public transportation, and 44 percent drove to campus alone (UC Berkeley 2012a). The transportation mode choice of UC Berkeley employees is partly a reflection of their housing location decisions. More than 80 percent of the employees live relatively close to cam-

Copyright 2016 Wei-Shiuen $\mathrm{Ng}$

http://dx.doi.org/10.5198/jtlu.2016.554

ISSN: 1938-7849 | Licensed under the Creative Commons Attribution - Noncommercial License 3.0

The Journal of Transport and Land Use is the official journal of the World Society for Transport and Land Use (WSTLUR) and is published and sponsored by the University of Minnesota Center for Transportation Studies. This paper is also published with sponsorship from WSTLUR and the Institutes of Transportation Studies at the University of California, Davis, and the University of California, Berkeley. 
pus and in areas with relatively good peak-period transit services, such as Berkeley, Oakland, and San Francisco (UC Berkeley 2012a). However, employees who live closest to the campus, i.e., within three miles of campus, tend to be in higher income households. This presents a social equity issue, where employees in lower-income households are unable to live closer to campus, as property values are relatively higher than in other regions, and hence they would have longer travel distances and travel times. While this study acknowledges the presence of social inequity in transportation choices and parking preferences, it is beyond the scope of this study.

Although the percentage of UC Berkeley employees who commute by private vehicles is significantly lower than the national average, which was 76 percent in 2009 (McKenzie and Rapino 2011), land for parking is scarce and improvements in campus parking management are still necessary. The campus provides approximately 6,400 parking spaces and has no desire to create new parking facilities due to their high capital and operating costs, environmental impacts, and neighborhood traffic concerns. Since activities on campus are expected to increase over time, efficient parking management and shifts in transportation mode choice are required if parking supply is to be capped at its existing level.

In addition to socioeconomic factors, the flexibility of work schedule can also lead to changes in transportation and parking behavior as it implies different travel time, duration of stay at primary work place, and frequency of commute trips. To better evaluate the impact of parking pricing and other transportation policies on travel behavior and demand, it is necessary to first understand how parking behavior can be influenced by employment type and its respective flexibility of work schedule.

A flexible work schedule and the availability of alternative parking locations can influence the effectiveness of parking pricing policies in the management of transportation and parking demand. The magnitude of the impact of parking pricing on travel behavior can also vary according to employment type and university affiliation, due to the differences in the flexibility of work schedule across academic disciplines, departments, and offices on campus.

It was initially hypothesized that employees with more flexibility in scheduling their own hours for being on campus would work off campus more often, be more willing to use transit and non-motorized modes, and drive to campus less. Another hypothesis is that higher flexibility of work schedule would also affect parking location, where employees with more flexibility would park off campus. However, as the following sections show, data collected from the one-on-one interviews indicate a far more complex and nuanced response.

\section{$2 \quad$ Work schedule in transportation studies}

The generic term "flexible work schedule" is used in this study for any work schedules that are not categorized as an 8 a.m. to 5 p.m., Monday through Friday, 40-hour workweek. This is a broad definition that encompasses both formal and informal work scheduling arrangements and working at home, as well as working a compressed workweek. Two common formal programs for flexible work schedules are alternative work schedules (AWS) and telecommuting, both of which are relevant to transportation and parking demand management. As defined by the U.S. Office of Personnel Management (2014), AWS can have designated hours and days beyond regular working hours or days, when an employee must be present for work or a compressed work schedule that is an 80-hour biweekly basic work requirement for less than 10 workdays. Telecommuting occurs when some or all of the work is performed at an offcampus location, either at home or at another office space. A work schedule can thus be flexible because of flexible hours, flexible days, or flexible location.

In addition to such formal arrangements, some employees may be allowed to set their own work schedules without having a formal agreement to do so, e.g., arriving on campus and departing at times that vary from day to day and deciding to work at home when convenient for them. At universities, 
professors and some other researchers and administrators often fall into this category.

One of the main benefits claimed for AWS and telecommuting is that the number of private vehicle trips and distance traveled can be significantly reduced. Studies have shown that telecommuting can reduce peak-hour trips and total distance traveled. Since commuters with very long trips may be disproportionately interested in AWS and telecommuting, telecommuting can produce trip reductions disproportionate to their travel distance numbers (Balepur, Varma, and Mokhtarian 1998; Kitamura et al. 1991; Mokhtarian 1991a; Pendyala, Goulias, and Kitamura 1991), leading to case-specific trip reductions. The reduction of private vehicle trips can decrease travel costs for employees, reduce congestion along the way to the workplace, and decrease energy use as well as emissions. In addition, telecommuting has also been found to decrease non-commute trips, due to the chaining of non-work trips to commute trips (Balepur, Varma, and Mokhtarian 1998; Pendyala, Goulias, and Kitamura 1991; Mokhtarian 1991b.)

Flexible work schedules have been researched extensively in transportation studies, especially in areas of peak-period congestion (Zhang et al. 2005; Smith 1984; Daganzo 1985; Braid 1989; Arnott, de Palma, and Lindsey 1993), road pricing (Emmerink and van Beek 1997; Saleh and Farrell 2005), improvement of road infrastructure utilization, transit services peak and off-peak utilization (Hendrickson and Plank 1984), and flexibility of departure time for work (Abkowitz 1981; Hendrickson and Kocur 1981). Discrete choice models based on random utility theory have also been applied to analyze peak-period congestion and trip scheduling (Small 1982; Ben-Akiva, Cyna, and de Palma 1984; Wilson 1989). Noland and Small (1995) and Bates et al. (2001) have included departure time choice in their discrete choice models for commuting trips.

However, fewer studies have examined how the flexibility of work schedules would affect mode choice and parking location preferences or how parking pricing would influence travel demand when work schedule is flexible. Mokhtarian (1991b) questioned the impact of telecommuting on ridesharing, while other studies (Mokhtarian et al. 1997; Wells et al. 2001) showed that employees drive alone more, use transit less, and use carpool or vanpool less, but walk or bicycle more on telecommuting days than on non-telecommuting days for general travel. These studies argued that although drive alone as a mode choice would increase on telecommuting days, overall trips will decrease in part because of a decline in trip chaining. Employees tend to chain personal trips (e.g., running errands) to work trips on non-telecommuting days. In one of the earlier studies on the impact of parking prices, Miller and Everett (1982) included flexible working hours in its analysis and concluded that work schedule induced transportation mode shift in certain employment sites in Washington DC. Gillen's (1978) parking location choice model for the central business district of Toronto found that when the flexibility of work hours is higher, individuals' parking duration will be shorter instead of finding parking locations with lower hourly parking rates.

Alexander, Dijst, and Ettema (2010) identified three main factors that contribute to a flexible work schedule, namely: 1) work-related characteristics; 2) information and communication technologies; and 3) socio-demographic characteristics, such as gender. Employees in managerial, professional, and clerical positions are more likely to have conventional work schedules (Vana, Bhat, and Mokhtarian 2008). Residential location also contributes to the flexibility of work schedules. Yeraguntla and Bhat (2005) found that employees living in highly urbanized areas have a greater flexibility in work schedule than employees living in suburban areas. Since UC Berkeley has a wide range of employment type and job characteristics, some more tied to campus facilities and service needs than others, it serves as a rich study site with varying levels of work schedule flexibility, leading to different transportation choices and parking preferences.

In this study, the flexibility of work schedule refers to the arrival and departure times of each em- 
ployee, frequency of trips to campus, and the duration of each trip on campus. The flexibility of work schedule is defined by arrival time, duration (number of hours on campus), frequency (number of days on campus per week), and location. This definition encompasses more than how most previous studies have defined flexibility of work schedule. Most studies have defined the flexibility of work schedule in relation to time of travel, especially departure time to work, and not the location of work and how many hours of work per day. For example, Toffler (1980) defined flexible work schedule as a family-friendly schedule that allows individuals to balance their work and domestic responsibilities. Yeraguntla and Bhat (2005) categorized work schedule flexibility as the possibility of arriving 30-45 minutes late at the workplace, while Alexander, Dijst, and Ettema (2010) defined the flexibility of work schedule as an employee's ability to choose when to start and end work.

\section{Methodology}

One-on-one interviews were conducted to examine how flexibility in work schedules will influence parking preferences. The ultimate goal of the interviews was to examine how the flexibility of work schedule would differ across academic fields and offices, and to identify the characteristics of UC Berkeley employees who are on campus more often than others. Interviewing is a basic mode of inquiry (Seidman 2006) and the purpose of interviewing is to understand the valuable lived experience and actions (Van Manen 1990) of a small sample of UC Berkeley employees to gain a clearer perception of how and why travel demand and parking preferences would be affected by employment type and work schedules. The data collected explain gaps found in existing campus transportation surveys and will be used to refine future transportation and parking survey questions by providing deeper insights.

A total of 86 one-on-one interviews with UC Berkeley employees, excluding student employees, were conducted over a period of two months from May to September 2013. The sample size of 86 represented a wide range of employment type, job levels, departments, offices, and academic disciplines. Each interview lasted between 30 and 60 minutes. Main questions were prepared before each interview, while follow-up questions were specific to participants' comments and can achieve depth and clarity when themes, concepts, ideas, or even events that the participants have described have been further explained. Probes were used to manage interviews by keeping them on topic and again to ensure depth and clarity (Rubin and Rubin 2005). The main interview questions (Appendix) were divided into 1) job description, 2) work schedule, and 3) preferred transportation mode choice, including parking preferences. Follow-up and probe questions were focused mainly on participants' attitudes toward telecommuting, official and unofficial policies within their departments or offices on alternative work schedules, resources on campus that are crucial to their work, and their personal experience with different transportation modes. Although every participant was asked the same number of main questions, the number of follow-up and probe questions depended on each individual's responses. Questions were matched to each respondent's unique travel experience, preferences, university affiliation, knowledge, and what each respondent was willing to share.

Participants for the interviews were selected based on university affiliation, job position, and nature of employment type to capture the anticipated range of flexibility in work scheduling. They represented different academic fields, disciplines, offices, and university services, which presumably reflect different work schedules and hence flexibility of work schedule and travel time. Faculty members were recruited from a range of academic fields to determine if there were disciplinary differences in travel patterns, e.g., the ability to work from home or the need to be physically present in a laboratory. Since UC Berkeley has more than 60 academic departments, six main academic fields were used to sample faculty. These six academic fields were: 1) Arts and Humanities; 2) Biological Sciences; 3) Mathematical and Physical Sciences; 4) Social Sciences; 5) Engineering; and 6) professional schools. Staff members were selected 
from three official job categories, as defined by UC Berkeley's Human Resources, which included: 1) operational and technical; 2) professional; and 3) supervisors and managers.

A list of faculty and staff members was first compiled using information (e.g., name, department, job title, and e-mail address) available on UC Berkeley's departmental websites. This sampling method is similar to what Patton (1980) described as "maximum variation sampling," which is a type of "purposeful sampling" technique that uses a few samples to represent a range of characteristics. Invitations to participate in the interviews were then sent electronically to 315 randomly selected UC Berkeley faculty and staff members across academic fields and departments or offices on campus in order to recruit at least 40 participants that represent a good mix of faculty and staff members from each of the above mentioned academic fields and job categories. The response rate for faculty was 26 percent ( 43 participants), which was slightly lower than the response rate for staff members at 28 percent ( 43 participants). Since there are approximately 10 staff members to every faculty member, the faculty members were disproportionately represented here. However, it was important to include at least 40 faculty members in the sample as they are the disproportionate users of central campus parking and highly influential stakeholders.

\section{$4 \quad$ Interview results}

The process of analyzing interview data involves classifying, comparing, weighing, and combining material from the interviews to derive patterns (Rubin and Rubin 2005). The data analysis process included the preparation of interview notes while finding, refining, and elaborating concepts, themes, and events. Concepts and themes found in all interviews were compared, while different individual events were combined to determine the relationship among work schedule and parking preferences. According to Rubin and Rubin (2005), a concept is a word that reflects an important idea that contributes to the research study, themes are statements that summarize and explain the behavior of participants, and events are occurrences that have taken place.

The description of the 86 participants is shown in Table 1, while Table 2 shows transportation and parking preferences. Data on the campus population are also provided in Table 1 for comparative purposes. The interview sample may not be a full representation of the campus population with respect to

all characteristics (e.g., gender) and job categories or academic disciplines included in this study, but it shows a wide range of employment type, which is more important in the qualitative analysis. 
Table 1: Summary statistics of participants

\begin{tabular}{|c|c|c|c|c|}
\hline & Interview sample & Percentage (\%) & Campus population $^{1}$ (2012) & Percentage (\%) \\
\hline \multicolumn{5}{|l|}{ Gender } \\
\hline Male & 48 & 56 & 3764 & 47 \\
\hline Female & 38 & 44 & 4233 & 53 \\
\hline Total & 86 & 100 & 7997 & 100 \\
\hline \multicolumn{5}{|l|}{ University affiliation } \\
\hline \multicolumn{5}{|l|}{ Faculty } \\
\hline Professor & 16 & 37 & 1003 & 66 \\
\hline Associate professor & 6 & 14 & 313 & 21 \\
\hline Assistant professor & 21 & 49 & 193 & 13 \\
\hline Total & 43 & 100 & 1509 & 100 \\
\hline \multicolumn{5}{|l|}{ Staff } \\
\hline Supervisors and managers & 11 & 26 & 1001 & 15.21 \\
\hline Professional & 29 & 67 & 3435 & 52.18 \\
\hline Operational and technical & 3 & 7 & 2138 & 32.48 \\
\hline Unknown & & & 9 & 0.14 \\
\hline Total & 43 & 100 & 6583 & 100 \\
\hline \multicolumn{5}{|l|}{ Academic discipline ${ }^{2}$} \\
\hline Arts and Humanities & 9 & 21 & 224 & 16 \\
\hline Biological Sciences & 3 & 7 & 195 & 14 \\
\hline Engineering & 7 & 16 & 222 & 16 \\
\hline Mathematical and Physical Sciences & 5 & 12 & 178 & 13 \\
\hline Social Sciences & 13 & 30 & 288 & 20 \\
\hline Professional schools ${ }^{3}$ & 6 & 14 & 307 & 22 \\
\hline Total & 43 & 100 & 1414 & 100 \\
\hline Total & 86 & & & \\
\hline
\end{tabular}

${ }^{1}$ Data presented on the population of employees by gender are for 2012 and only represent active, paid and permanent staff (UC Berkeley $2012 \mathrm{~b}$ ) and professorial tenured and professorial non-tenure faculty members (UCOP 2013). Data on the population of staff members by job category also only reflect active, paid, and permanent staff members (UC Berkeley 2012b). Faculty data by job category for 2012 were obtained from Cal Answers (UC Berkeley 2015).

${ }^{2}$ Professorial tenured and professorial non-tenure faculty members only.

${ }^{3}$ Professional schools include Business and Management, Education, and Law.

Table 2: Transportation mode choice and parking location of participants

\begin{tabular}{lcccc}
\hline & Faculty & Staff & All Employees & Percentage (\%) \\
\hline Transportation mode choice & & & & \\
Drive alone & 17 & 17 & 34 & 40 \\
Carpool & 0 & 1 & 1 & 1 \\
Motorcycle & 1 & 0 & 1 & 1 \\
Bus (e.g., AC Transit ${ }^{1}$ ) & 1 & 4 & 5 & 6 \\
Train (e.g., BART ${ }^{\text {) }}$ & 5 & 9 & 14 & 16 \\
Bicycle & 8 & 4 & 12 & 14 \\
Walk only & 10 & 6 & 1 & 19 \\
Dropped off & 1 & 0 & 2 & 1 \\
Telecommuting (full time) & 0 & 2 & 86 & 2 \\
\hline Total & 43 & 43 & & 100 \\
\hline Parking location choice & & & 25 & 74 \\
On campus & 12 & 13 & 9 & 26 \\
Off campus & 5 & 4 & 34 & 100 \\
\hline Total & 17 & 17 & & \\
\hline
\end{tabular}

${ }^{1}$ AC Transit is a bus system in Alameda and Contra Costa counties, and it has direct services to the UC Berkeley campus.

${ }^{2}$ BART is the Bay Area Rapid Transit. 


\subsection{Job description and work schedule}

The job descriptions of most professors are similar across academic disciplines, but staff members have a wider range of responsibilities that are harder to generalize. For faculty members, common job descriptions include teaching, conducting research, managing research centers, advising students, attending seminars and committee meetings, committing to administrative duties, and participating in regular off-campus meetings. For staff members, jobs can be either desk-bound or non-desk bound. Most staff members have desk-bound jobs, and those with non-desk jobs are often moving around the campus at different times of the day. Unlike staff members, most of the work-related activities for faculty members, apart from teaching, are not at fixed times but scheduled at the faulty member's discretion.

"I teach several courses a year, advise students, reading, writing, thinking, and going to seminars. I work quite independently, not in teams. I teach three formal courses and help teach two courses a year. I travel a lot and spend more time working off campus than on campus." (Faculty member, Social Sciences)

Faculty members have a more flexible work schedule than staff members and are usually on campus less frequently, either by number of days per week or by number of hours per day. However, although faculty members may have more flexible work schedules than staff members and have the option to work from home or somewhere else off campus, some faculty members prefer to be on campus and work on campus just like staff members with a regular 9 a.m. to 5 p.m., Monday to Friday, schedule.

"My department is flexible and does not really care if faculty members are on campus or not. Staff members at the department are allowed to work from home, but it is rare. They can work from home due to family emergencies or commitments, but every staff member is here on campus from Monday to Friday." (Faculty member, Social Sciences)

Regardless of university affiliation, most of the participants arrive on campus between $7 \mathrm{a} . \mathrm{m}$. and 10 a.m. and depart between 4 p.m. and 8 p.m. Arrival and departure times are similar for both faculty and staff members, but for employees with young children, commute hours are usually dictated by their children's daycare or school hours.

"I arrive at 8 a.m. or 9 a.m. and leave at 5 p.m. or 6 p.m. My schedule is constrained by daycare hours." (Staff member, professional)

The biggest difference in work schedules between faculty and staff members lies within the frequency of work trips per week. It is more likely for faculty members to be working from home before and after regular working hours than for staff members, though it is also common for senior staff in managerial roles to take work home. Working from home also means working off campus during regular office hours, i.e., telecommuting. This will replace the need to be on campus and is found to be more common among faculty members, though not a lot more. Out of all the faculty members interviewed, 63 percent (27 participants) were on campus for at least five days a week during a typical semester, while the rest were on campus three or four days a week and worked from home when they were not on campus. The decision to work or not work from home depends on a few main factors, which vary according to each individual's preferences and department's tradition. The most common factors mentioned throughout the interviews were crucial resources on campus, attitudes toward telecommuting, availability of home office, and the number of professional and social activities held within each department. 
"It is possible for me to work from home. I have a home office, which is better and bigger than my office at the department. I have the same computer at home and all my books are at home. I would prefer to work from home, but there are things that can be done better on campus, e.g., teaching or meeting students, but writing is better off campus." (Faculty member, Social Sciences)

For faculty members, academic fields matter to a certain extent, as each field has a different level of dependence on physical assets and resources that are located on campus, affecting the ability to work off campus. Important resources on campus include both physical assets, such as laboratories, libraries and computers, and people, including students, colleagues, and research staff. This definition of resources is the same for both faculty and staff members. Some staff members' daily responsibilities rely on internal servers and software, which are only available on campus, or they play managerial roles in their offices. To these staff members, there are no gains from telecommuting, and they would prefer to be on campus than not.

"My current role makes it harder to work from home. It is a campus culture; people expect me to talk to them in person. The university does not quite accept communicating remotely. As a manager, I allow working from home for my staff, but it is harder for me to do so myself." (Staff member, supervisors and managers)

Faculty members who do not use unique campus resources have been found to be working on campus just as often as faculty members who require specific resources only available on campus. Hence, not all faculty members who are on campus every day of the workweek are so because they need specific equipment or facilities only found on campus for their work. A significant percentage of faculty members are only on campus on days they teach or have other appointments (37 percent of faculty interviewed, i.e., 16 participants). Apart from resources on campus, attitudes toward working on campus and from home play a significant role in determining how often a faculty member is on campus. Some faculty members simply prefer working on campus because they want to be available for their students beyond regular office hours and believe their students' productivity will decrease when they are not around. For these professors, working from home is not as efficient as being on campus because they prefer to interact with students and colleagues. Faculty members with administrative duties will also need to be on campus more often than faculty members without.

"It is possible for me to work from home, but I do not do it. I am on campus every day, from Monday to Friday. There are people whom I work with in my lab, four graduate students, three research assistants, and many undergraduates. I share an office space with them, and I believe my lab is happier when I am around. I prefer to be on campus and interact with my students every day." (Faculty member, Biological Sciences)

The type of tasks to be accomplished is another important reason why some faculty members choose to work on campus on certain days and when not to. Although different faculty members have different preferences regarding which tasks are better accomplished on campus and which are not, it is possible to generalize that certain tasks, such as meeting students, are better conducted on campus, while writing and preparing lectures are tasks that almost all faculty members who are on campus for less than five days a week prefer to do off campus. Basically, most faculty members prefer to write without being interrupted or distracted, though there was one faculty member who believed that interruptions and 
conversations with other people during the day help "keep things fresh." Whether working on or off campus is more distracting is highly dependent on individual experience and preference. For example, some faculty members have mentioned that they find it distracting to work from home because of their pets or they would spend time cooking or cleaning, while others find it harder to focus on campus when they are often interrupted by students or colleagues. Some faculty members also prefer to have a mix of environment, with one citing "a variety of surroundings helps keep my mind better to focus."

Frequent interactions with colleagues are also important for at least four faculty members, who strongly believe that "shared experience is important," "people are dramatically more creative when they are surrounded by other creative people and learn from each other," and "socializing with colleagues on campus is useful and enjoyable." There is also one professor who schedules daily lunch meetings with colleagues, "sometimes socially or just to talk science." These findings could explain why the majority of the faculty members do not prefer to work from home even when they do not need access to any unique campus resources that are crucial to the success of their work.

The most common reason to work off campus is the availability and quality of an alternative working environment, which can be a home office, or a cafe on campus or near a faculty member's residential location. Faculty members who prefer to work from home at least once a week have specifically described their home offices as "better and bigger," "nicer," "more conducive to thinking," "more comfortable," and with the same if not better resources, i.e., computers and books, when compared to their offices on campus.

The attitude toward telecommuting is very different for staff members. All of the interviewed staff members are on campus for at least five days a week, unless they have arranged for alternative work schedules with their supervisors, in which case, they will take every other Friday off. Depending on the department or office of the participant, most staff members are not encouraged to work from home, and apart from full-time telecommuters, none of them work from home on a regular basis. Some staff members have worked from home previously under special circumstances, e.g., after having a baby or surgery. Most of the staff members have never even considered the possibility of working from home. In addition, none of the supervisors and managers interviewed will allow their staff to work from home on a regular basis, citing reasons such as, "it is easier to collaborate face-to-face," "there is a lot of loss when staff are working from home and not communicating with one another," and "it is important to be on campus every day."

\subsection{Flexibility of work schedule and parking preferences}

UC Berkeley provides paid parking spaces at various locations on campus, at rates that run from $\$ 29$ to $\$ 124$ a month, as well as daily parking permits ranging from $\$ 6$ to $\$ 16$, depending on location and university affiliation (UC Berkeley 2013). At the same time, public and private garages and lots, metered spaces, and spaces in the residential preferential parking (RPP) zones surrounding the campus offer alternatives for those who choose not to use on-campus parking spaces. Some of the participants make use of public and private garages that offer daily parking at rates ranging from $\$ 9$ (early bird rate) to $\$ 16$ a day, paying for parking only on the days they need it. Some make use of metered spaces, with some staying for short periods only and others moving their cars from space to space. Metered spaces and nonresident parking in unmetered RPP zones are legally restricted except for those who are making a trip of limited duration (under two hours), but enforcement is imperfect and those who are willing to feed the meter or move their cars after two hours generally can avoid a ticket. At the time of the study, meter rates were $\$ 1.25$ per hour and most metered spaces allowed either one hour or two hours of parking. Rates at some meters have since been raised and time limits in a few locations have been lengthened, but RPP zones still limit non-resident parking to two hours (Moylan, Schabas, and Deakin 2014). 
Among the off-campus parkers in the interview sample, RPP neighborhoods are a popular location for both faculty and staff members to park their vehicles during regular working hours. Faculty members for the most part are using these spaces for short durations, on days when they do not have to be on campus for more than two hours. As described in the previous section, faculty's work schedules are considerably more flexible than staff members, and even if they choose to be on campus every day, they are neither expected to nor do they necessarily stay on campus all day. Staff members, in contrast, reported for the most part that they were expected to be on campus for most of the day, i.e., between six to nine hours, and for those who park in RPP zones, they would need to move their vehicles to avoid parking tickets. In other words, both faculty and staff members choose to park in RPP zones, but faculty members do so because it is convenient due to their flexible work schedules, whereas staff do so to avoid paying for parking and move their vehicles up to three or four times a day.

The majority of faculty and staff members, 74 percent, (25 participants) (Table 2) who drive to campus have a campus annual parking permit and park at one of the campus parking garages or lots. Staff members who drive and hold a campus parking permit have no incentive to park elsewhere but on campus, since they have already paid for a parking permit and will not consider using any type of offcampus parking. Staff members with campus parking permits believe that it is more convenient to park on campus and not have to move their vehicles around because of the time limit enforcements in RPP neighborhoods. They are also more likely to be staff members in "supervisors and managers" positions, which offer little flexibility in work schedules.

"I would never park on the streets. It is such a hassle and disruption to the work flow. I don't want to deal with that. It is not worth it. I know people who move their cars four to five times a day, and if each moving time takes 15 minutes that would be an hour gone." (Staff member, supervisors and managers)

Among the faculty members interviewed who currently hold a campus annual parking permit, few have ever considered any other parking locations. Most have had a campus parking permit ever since they started working at UC Berkeley. A few of the faculty members in this group mentioned that they are aware of the availability of free parking in RPP zones surrounding the campus but have never considered those parking spaces as an option for their parking needs. When one faculty member was asked if he had ever tried to use street parking, he responded, "Why? I have a parking permit."

Not all participants who drive to campus hold an annual UC Berkeley campus parking permit, which implies that not all drivers park on campus. Almost 30 percent of all the UC Berkeley employees (25 participants) interviewed, regardless of faculty or staff, do not hold an annual parking permit but drive to campus on a regular basis. As shown in Table 2, 26 percent of faculty and staff members ( 9 participants) park at off-campus locations, and the percentage of faculty members who do so is slightly higher than staff members. Although the number of faculty and staff members who park off campus is similar, they choose to park off campus for different reasons.

Staff members who choose to park off campus are usually concerned with the cost of parking on campus and are willing to move their vehicles up to four times a day and risk getting a parking ticket to avoid paying for parking. Most of them move their vehicles up to four times a day, and two participants have described it as an enjoyable "parking game" and use it as a form of exercise. Since employees who park in the residential areas need to move their vehicles every hour or two, the nature of their jobs and responsibilities have to be flexible enough for them to do so. This implies that they are not expected to be in their offices at all times and, for example, do not have long meetings throughout the day, which means parking in residential areas is not an option for employees in all job categories. Employees with 
inflexible work schedules are less likely to use off-campus parking.

"I park in the residential neighborhood every day. My current parking location is about a two to three minute walk from my office. I move my car three to four times a day, and I use it as a form of exercise and like it." (Staff member, professional)

Among faculty members, those who have access to more than one transportation mode or prefer to not drive every day will park off campus more frequently than faculty members who prefer to drive every day. Faculty members who are not on campus every day or those who are only on campus for a few hours a day tend to use off-campus parking spaces too.

"I drive to campus but do not have a parking permit. I schedule my classes late in the day so that I can park after 4 p.m. and pay for no more than two hours of metered parking. I have a flexible schedule and only need to be on campus two days a week, when I teach on campus." (Faculty member, Arts and Humanities)

"I only park in the residential neighborhoods about once a week when I am only on campus for two hours or less. If I stay on campus for more than two hours, I would use a daily permit. Where I park depends on whether I have classes to teach, my expected time on campus, if I am carrying heavy things, and overall timing." (Faculty member, Social Sciences)

Participants, regardless of faculty or staff members, who choose to park in RPP zones are willing to take the risk of getting a parking citation and almost all of them receive a citation once in a while. Some receive a citation once every six months on a regular basis and prefer to pay a parking citation than for an actual parking space.

"When I park in the residential neighborhoods, I move my vehicle every two hours. I have not got a ticket in years. I park in the residential neighborhoods only about once a week, when I am only on campus for about two hours." (Faculty member, Social Sciences)

"I receive about 10 parking tickets a year and use a campus daily parking permit about once or twice a month on days when I know I will be on campus for more than eight hours and will not making any other trips in between." (Staff member, professional)

It is also more likely for staff members who are not regular drivers to park in residential neighborhoods when they drive to campus occasionally. This is a group that prefers to use other forms of transportation modes as their primary mode choice.

\section{Discussion}

The interviews provided some insights on UC Berkeley faculty and staff members' work schedules and parking preferences. Based on the interview results, the flexibility of work schedules for faculty is highly dependent on each individual's preferences. Faculty members who are on campus for at least five days a week do so not because they have to but rather because they prefer to be available for their students and interact with colleagues or because of the tradition within their departments.

Staff members' work schedules are less flexible across all job categories compared to faculty members' schedules, but all work schedules, in general, seem to affect parking location, whether on or off 
campus. In particular, those who arrive on campus later in the day or stay for longer hours on campus are more likely to drive and park on campus. It is important to emphasize that almost 40 percent of the faculty members (17 participants) interviewed are not on campus five days a week, leading to a significant impact on their parking demand and preferences.

\subsection{Telecommuting and alternative work schedules are uncommon among staff members}

Not all staff members are eligible for AWS or are able to work from home without affecting their productivity. The higher the job level, the less likely it is possible for an employee to work from home during regular business hours or to arrange to be on campus for less than five days a week. This finding is consistent with Vana, Bhat, and Mokhtarian's study (2008). Managers and supervisors often need to interact with their team members and supervision of staff is best done in person. There are also certain jobs that require the physical presence of an employee on campus to accomplish specific tasks, and telecommuting would thus be infeasible. Based on the interview results, some examples of such job titles include laboratory assistants, campus fire marshals, health and safety specialists, and most jobs within the "operational and technical" job category as defined by the university. In fact, the "professional" job category is the only group that is likely to be able to work from home or arrange AWS. Other than job category, the ability to telecommute or arrange for AWS also depends on common practice within a specific department or office, particularly what an employee's supervisor considers to be most appropriate.

In the abstract, the idea of telecommuting seems to be a perfect solution to the problems of increasing travel demand, congestion, energy use, and air pollution. Employees would work from home using technologies that will enable them to communicate and work as productively as they would at their workplace. However, in reality, telecommuting is simply not for every job category or every level within each job category. Most departments do not encourage telecommuting and AWS, and instead prefer their staff members to be on campus. In some cases, this is because the jobs require the physical presence of the employees, but in other cases, it is because managers believe face-to-face contact is important or simply because of tradition. As a result, less than 10 percent of the staff members ( 4 participants) interviewed have flexible work schedules. Although almost all participants cited computers as a crucial resource for their work, there are other resources that cannot be replaced by technology, such as people. Staff members rely on one another more than faculty members do. Faculty members who choose to work on campus at least five days a week often cited the need for working together in lab settings, but some also reported that they prefer to come to work five days a week not because they need to but rather because they enjoy social and professional interactions with their colleagues and students. Just because an employee has a computer-based, desk-bound job does not necessarily mean that it is possible or more preferable to work off campus.

Although the flexibility of work schedules is in general higher for faculty than staff members, faculty members follow self-imposed schedules, and if they are on campus, they will stay on campus for at

least seven or eight hours, just like staff members do. This implies that future changes in parking pricing could have a low impact on parking duration for staff members and for faculty members who are already on campus at least five days a week. In other words, once an employee has chosen to drive to campus, parking duration is unlikely to be altered under a different parking-price scenario.

\subsection{Personal preferences have the highest impact on work schedule for faculty members}

The preference to work on campus or not, regardless of academic discipline, is one of the most important factors contributing to faculty members' work schedules. Personal preference has a higher impact on work schedule than job description, since other than teaching, advising students and attending com- 
mittee meetings on campus, everything else a faculty member does will not be subject to a location constraint. Faculty members who do not need access to any unique physical resources on campus prefer to work on campus and be on campus for at least five days a week for reasons irrelevant to their academic disciplines. Faculty members who choose to be on campus for less than five days a week or who are only on campus on days they teach do so because they prefer to work from home, regardless of their academic discipline.

Academic discipline only influences the flexibility of work schedule to a certain extent. Faculty members in natural sciences who have invested in equipment in their laboratories are more likely to be on campus for at least five days a week. However, a laboratory can also consist of people and simple equipment, such as computers. The need and preference to be on campus are mostly not due to physical resources but to people. Faculty members in Biological Sciences, Engineering, and Mathematical and Physical Sciences tend to be on campus more often than faculty members in Arts and Humanities and Social Sciences because even if they do not require access to specific physical resources on campus, they often need to manage bigger groups of students and researchers in their laboratories and prefer to be available for them on a regular basis. In certain departments, it is also tradition to be on campus, even though faculty members are self-sufficient and do not need to be on campus for at least five days a week to stay productive.

\subsection{Employees with flexible work schedules use off-campus parking more}

Work schedule has a significant impact on parking location choice, especially for employees who do not have fixed arrival or departure times, do not need to be on campus every day of the week, or do not stay on campus for more than two hours per day. The University provides paid parking spaces at various locations on campus, but the more popular campus parking lots or garages are usually fully occupied by a certain time in the morning. If employees do not arrive on campus early enough, there might be no parking spaces left by the time they arrive. For faculty and staff members who are on campus early in the mornings, e.g., before 8:30 a.m., parking will not be a problem on campus, but others who live farther away and arrive later, would choose to park off campus. Depending on where an employee's primary workplace is located on campus, residential parking zones may not be farther away from where they work than an on-campus parking lot or garage. In some cases, walking distance is similar. Off-campus parking locations can thus be competitive parking alternatives to on-campus parking in terms of both cost and walking time

\section{Conclusions}

The interview sample in this study is broadly representative of the campus faculty and staff and so with some caution can be used to draw tentative conclusions and supplement future campus survey results for UC Berkeley or other large employers. Driving alone is the most popular mode choice among all university affiliates and job categories. However, not all university affiliates who drive have the same parking location preferences. While price affects parking choice, so do the time constraints created by both work schedules and personal schedules. Employees may choose to park off campus because of costrelated reasons, but only a select group of employees with flexible work schedules can do so. Employees who are on campus for longer hours per day or more days per week tend to park on campus more than those who are on campus for fewer hours or days.

The availability of parking alternatives off campus has created choices that are cost and time (walking) competitive to on-campus parking. Employees with flexible work schedules are able to park off campus in residential neighborhoods and move their vehicles regularly throughout the day to avoid 
getting a ticket. Since their working hours are more flexible, they can also choose to have a mix of different parking locations, i.e., park on campus on days when they have to be on campus for eight hours or more, and use metered on-street parking on days when they only have to be on campus for two hours or less.

While many faculty and staff members who drive park in residential neighborhoods surrounding the campus, few worried about the legality of overstaying the parking time limits. Without stricter enforcements for limiting from the city of Berkeley, there is little pressure for behavioral change being put on employees who use the residential neighborhoods as a source of free parking. On the other hand, if parking off campus in residential neighborhoods with time limit enforcement (i.e., two hours) is no longer an option or becomes more costly, more current users of this parking supply may turn to the campus for parking. Employees who currently park off campus have already established a routine of their own that offers an acceptable parking option independent from any policy changes the campus may make. Future parking policies should consider parking alternatives that are available to commuters to better manage transportation and parking demand.

The magnitude of the impact of parking pricing on mode choice and parking location choice can vary according to job characteristics and flexibility of work schedules. This study has only presented an overview of the linkages among these choices and preferences. A more in-depth analysis is required to further understand how influential the flexibility of work schedules can be. 


\section{References}

Abkowitz, M. D. 1981. An analysis of the commuter departure time decision. Transportation 10: 283297.

Alexander, B., M. Dijst, and D. Ettema. 2010. Working from 9 to 6? An analysis of in-home and outof-home working schedules. Transportation 37: 505-523.

Arnott, R., A. de Palma, and R. Lindsey. 1993. A structural model of peak-period congestion: A traffic bottleneck with elastic demand. The American Economic Review 83(1): 161-179.

Balepur, P. N., K. V. Varma, and P. L. Mokhtarian. 1998. Transportation impacts of center-based telecommuting: Interim findings from the neighborhood telecenters project. Transportation 25: 287306.

Bates, J., J. Polak, P. Jones, and A. Cook. 2001. The valuation of reliability for personal travel. Transportation Research Part E 37: 191-229.

Ben-Akiva, M., M. Cyna, and A. de Palma. 1984. Dynamic model of peak-period congestion. Transportation Research B 18(4/5): 339-355.

Braid, R. M. 1989. Uniform versus peak-load pricing of a bottleneck with elastic demand. Journal of Urban Economics 26: 320-327.

Daganzo, C. F. 1985. The uniqueness of a time-dependent equilibrium distribution of arrivals at a single bottleneck. Transportation Science 19(1): 29-37.

Emmerink, R. H. M., and P. van Beek. 1997. Empirical analysis of work schedule flexibility: Implications for road pricing and driver information systems. Urban Studies 34(2): 217-234.

Gillen, D. W. 1978. Parking policy, parking location decisions and the distribution of congestion. Transportation 7: 69-85.

Hendrickson, C., and G. Kocur. 1981. Schedule delay and departure time decisions in a deterministic model. Transportation Science 15: 62-77.

Hendrickson, C., and E. Plank. 1984. The flexibility of departure times for work trips. Transportation Research Part A 18(1): 25-36.

Kitamura, R., P. Mokhtarian, R. Pendyala, and K. Goulias. 1991. An evaluation of telecommuting as a trip-reduction measure. Working Paper No. 5. Berkeley, CA: The University of California Transportation Center, University of California at Berkeley.

McKenzie, B., and M. Rapino. 2011. Commuting in the United States: 2009. U.S. Census Bureau. http://www.census.gov/prod/2011pubs/acs-15.pdf.

Miller, G. K., and C. T. Everett. 1982. Raising commuter parking prices—an empirical study. Transportation 11: 105-129.

Mokhtarian, P. 1991a. Telecommuting and travel: State of the practice, state of the art. Transportation 18: 319-342.

Mokhtarian, P. 1991b. An empirical analysis of the transportation impacts of telecommuting. Working Paper UCTC No. 131. Berkeley, CA: The University of California Transportation Center, University of California at Berkeley.

Mokhtarian, P., C. Ho, S. Hung, T. Lam, E. Raney, L. Redmond, D. Stanek, and K. Varma. 1997. Residential area-based offices project: Final report on the evaluation of impacts. Research Report UCDITS-RR-97017. Davis, CA: Institute of Transportation Studies, University of California Davis.

Moylan, E., M. Schabas, and E. Deakin. 2014. Residential permit parking: Better off without it? Transportation Research Record 2469: 23-31.

Noland, R. B., and K. A. Small. 1995. Travel-time uncertainty, departure time choice, and the cost of morning commutes. Transportation Research Record 1493: 150-158. 
Patton, M. Q. 1980. Qualitative evaluation methods. Thousands Oaks, CA: Sage Publications.

Pendyala, R. M., K. G. Goulias, and R. Kitamura. 1991. Impact of telecommuting on spatial and temporal patterns of household travel. Transportation 18: 383-409.

Rubin, H. J., and I. Rubin. 2005. Qualitative interviewing: The art of hearing data. Thousand Oaks, CA: Sage Publications.

Saleh, W., and S. Farrell. 2005. Implications of congestion charging for departure time choice: Work and non-work schedule flexibility. Transportation Research Part A 39: 773-791.

Seidman, I. 2006. Interviewing as qualitative research: A guide for researchers in education and the social sciences. Third Edition. New York: Teachers College Press.

Small, K. A. 1982. The scheduling of consumer activities: Work trips. The American Economic Review 72(3): 467-479.

Smith, M. J. 1984. The existence of a time-dependent equilibrium distribution of arrivals at a single bottleneck. Transportation Science 18(4): 385-394.

Toffler, A. 1980. The third wave. New York: William Morrow.

UC Berkeley. 2012a. 2012 Transportation and housing survey. Unpublished raw data. Berkeley, CA: Department of Parking and Transportation, University of California Berkeley.

UC Berkeley. 2012b. Workforce profile: Demographics and statistical information. Human Resources, University of California Berkeley. URL: http://hrweb.berkeley.edu/diversity/demographics/workforce-profile.

UC Berkeley. 2013. Parking facility survey. Unpublished raw data. Berkeley, CA: Department of Parking and Transportation, University of California Berkeley.

UC Berkeley. 2015. 2012 Trends by job type. Unpublished raw data. Cal Answers. Berkeley, CA: Human Resources Census, University of California Berkeley.

UCOP. 2011. The University of California statistical summary of students and staff. Fall 2011. Department of Information Technology Services, Office of the President, University of California. URL: http://www.ucop.edu/ucophome/uwnews/stat/.

UCOP. 2012. University of California Berkeley full-time and part-time headcount: Personnel tables. Corporate Personnel System, University of California Office of the President. URL: http://www. ucop.edu/ucophome/uwnews/stat/headcount_fte/apr2012/er1bkh.pdf.

UCOP. 2013. Headcount of UC Berkeley faculty. Unpublished raw data. Berkeley, CA: Corporate Personnel System, University of California Office of the President.

U.S. Office of Personnel Management. 2014. Handbook on alternative work schedules. OPM. http:// www.opm.gov/policy-data-oversight/pay-leave/reference-materials/handbooks/alternative-workschedules\#Core Hours.

Van Manen, M. 1990. Researching lived experience: Human science for an action sensitive pedagogy. London, Ontario: Althouse Press.

Vana, P., C. R. Bhat, and P. L. Mokhtarian. 2008. On modeling the choices of work-hour arrangement, location, and frequency of telecommuting. Research Report UCD-ITS-RR-08-48. Davis, CA: Institute of Transportation Studies, University of California Davis.

Wells, K., F. Douma, H. Loimer, L. Olson, and C. Pansing. 2001. Telecommuting implications for travel behavior. Case studies from Minnesota. Transportation Research Record 1752: 148-156.

Wilson, P. W. 1989. Scheduling costs and the value of travel time. Urban Studies 26: 356-366.

Yeraguntla, A., and C. Bhat. 2005. Classification taxonomy and empirical analysis of work arrangements. Transportation Research Record 1926: 233-241.

Zhang, X., H. Yang, H. Huang, and H. M. Zhang. 2005. Integrated scheduling of daily work activities and morning-evening commutes with bottleneck congestion. Transportation Research Part A 29: $41-60$. 


\section{Appendix}

Faculty and Staff Interview Guide

May-August 2013

Exploring University of California Berkeley Employee Commuting Choices and Parking Preferences

\section{Part One: Interviewee Background and Experiences}

1. How long have you been...

in your present position?

at UC Berkeley?

2. Could you give me a brief overview of what it is you do in your work?

Probes: Is your work computer/laboratory/library (or other resources) based? Could you possibly work from home if you want to? Why or why not? What percent of the time could you work at home? Would you prefer to work from home (or at any other off-campus location) or work on campus if you have a choice (reasons, influences, experiences)? Is this a common practice at your department?

How much time (percentage) would you spend teaching, meeting students and working on research projects in your office during a workweek?

Notes: Working from home could mean working at home during regular work hours or working at home before or after regular working hours, e.g., during the evenings or on weekends. I am interested in the former definition.

3. Could you describe some of the resources on campus that are crucial to your work?

Probes: For example, some faculty and staff rely on certain equipment in laboratories, some may need to use supercomputing facilities, while others may need to work in art studios or use manuscripts stored in libraries on campus. What are some of the common resources that your department/ office needs?

4. Could you tell me about your work schedule this semester?

Probes: How often do you usually come to campus per week?

How long do you usually stay on campus?

What is your typical arrival and departure time when you come to campus?

Does your schedule change in the summer?

5. Does your job require you to be off campus (e.g., for meetings) on a regular basis?

Probes: Where are such events usually held? For example, do members of the department have labs 
in Richmond Field Station or at LBL? Or do they do field work that requires them to be out in the community or out of the country?

How would you travel to such events?

Do you have another office not on central campus (e.g., for people who are in Physics, Chemistry, Engineering, etc., they might have offices away from the central campus, i.e., LBL, RFS)?

\section{Part Two: Department/Office Characteristics and Culture}

6. How often do you see or interact with your colleagues?

Probes: Through what kind of events or activities will you usually see your colleagues? Examples include faculty meetings, weekly seminars, staff events, etc.

How many full-time faculty/staff members are there in your department?

Are there any part-time faculty/staff at this department? If so, how many?

\section{FOR STAFF MEMBERS ONLY}

7. Does your department/office permit alternative or variable work schedules for staff members?

Probes: If so, what is the approximate percentage of staff working on alternative work schedules? Alternative work schedules are schedules that are not five days at eight hours. What are the alternative work hours? For example, are they part time but work 8 a.m. to 5 p.m. when they do come in, or do they schedule their own hours to arrive and leave? Do they schedule to work from home or not? Or do they work four 10-hour days a week or work from home on Fridays?

8. How common is it for staff members to work from home at your department/office?

Probes: If not, do most staff members follow a regular daily routine, e.g., eight hours/day for five consecutive days within a week? If not, what are their work schedules like?

\section{FOR FACULTY MEMBERS ONLY}

9. How common is it for faculty members to work from home or take their work home at your department?

Probes: If not, what are most faculty members' work schedules like? Do faculty members follow a regular daily routine, e.g., eight hours/day for five consecutive days within a week? What is the approximate percentage of faculty members who work from home regularly?

\section{Part Three: Transportation and Parking}

10. How do you usually commute to campus?

11. Could you describe your experience with your daily transportation mode? 
Probes: How about your experience with other transportation modes that you have tried? E.g., congestion and where are the congested routes. Is there variability in your travel time?

12. Have you considered using other types of transportation modes?

Probes: Have you ever driven, taken public transportation, carpooled, biked or walked to campus since you started working at UC Berkeley? What were the causes of the change in transportation mode?

13. If you drive, where do you usually park your vehicle?

Probes: Is your parking location on campus or off campus? If on campus, which parking garage/lot would you park at? Do you always park at the same location? How long does it take you to walk to your office from your parking space? Would you consider paying a premium price for a parking space closer to your office? Or would you rather pay less for a parking space that is located farther away from your office?

14. What do you think about your current commute/parking cost?

Probes: If you use public transportation, do you have a Bear Pass (subsidized AC Transit pass)? Would you consider driving to campus if parking were free? How about if there were a more flexible daily parking permit that removes the existing annual commitment? Would such a permit make you drive more?

If you park on campus, what do you think of the current parking prices? How about a more flexible daily parking permit that allows you to pay per day or per hour parked, either pay by machine or pay by cell phone? Do you think such a permit would make you drive less? 